\title{
Comparison of Beneficial Effects of Kinesiotherapy for Seasonal and Non-Seasonal Depression
}

\author{
By Arcady Putilov* \\ Boris Pinkhasov ${ }^{\dagger}$
}

\begin{abstract}
Although kinesiotherapy is usually used for improvement of a person's endurance, mobility and strength, it can be also beneficial for different mood disorders including depression. We compared the clinical effects of several types of one-week mono and combined treatments in women with non-seasonal depression, seasonal depression and without depression. A week of kinesiotherapy was equally beneficial for nonseasonal and seasonal depression. A week of bright light therapy produced a similarly strong antidepressant response only in seasonal depressives. One-week therapies with exercise and/or bright light prevented relapse and produced further improvement after night sleep deprivation. However, if at least one of such treatment modalities ensured excellent response, there was no additional benefit from their combination. Since the specific feature of depression is that only in this illness a placebo effect can be very strong, these results highlighted once again the possibility that "visible" one-week interventions can work mostly as powerful placebos.
\end{abstract}

Keywords: Kinesiotherapy, Bright Light, Sleep Deprivation, Antidepressant and Placebo Response, Depression.

\section{Introduction}

Depression appears to be a much more common disease than other mental disorders. It is ranked fourth in the world in terms of the global burden of disease (Murray and Lopez 1996, Üstün et al. 2004). Therefore, it is of great practical importance to examine the possible clinical benefits offered by its treatment with antidepressants (Andrews 2001). However, the clinical trials have aroused concern among researchers and the lay public about efficacy of the conventional (pharmacological) antidepressant treatments. For instance, the general negative view that the public have about the benefits of medications (Jorm et al. 1997) was supported by clinical trials indicating that many pharmacological agents act nonspecifically and are not distinctly superior to placebo treatments (Joffe et al. 1996, Moncrieff et al. 1998, Antonuccio et al. 1999, Khan et al. 2000, Kirsch et al. 2008, Moncrieff 2002, Walsh et al. 2002). The major problem with any antidepressant medications prescribed for depression is that there is no other illness in which the placebo effect is so large, either in absolute terms or as a proportion of the change in the treatment group. For instance, placebo groups

\footnotetext{
${ }^{*}$ Chief Researcher, The Research Institute for Molecular Biology and Biophysics, Russia.

${ }^{\dagger}$ Senior Researcher, The Scientific Centre of Clinical and Experimental Medicine, Russia.
} 
comprise $60 \%$ of the progress recorded in the drug-treated groups, whereas it is only $23 \%$ in agoraphobia, $21 \%$ in obsessive-compulsive disorder and no progress at all in schizophrenia (Andrews 2001).

Physical activity has been shown to be beneficial in alleviating depression (Lawlor and Hopker 2001, Martinsen 2008). However, researchers are seriously concerned about the placebo action of kinesiotherapeutic interventions. Indeed, since depressed patients cannot be "blind" to such a therapy, they do not need to guess on which of the interventions is an active treatment. Consequently, a placebo response is expected to be enlarged due to "visibility" of the treatment with physical exercise. To resolve this problem researchers often focus on the differences between clinical effects of two "visible" treatments, one of which can be regarded as an active treatment and another as a placebo treatment.

In 2000, we published the preliminary results on comparison of the clinical effects of one-week mono-treatments with either bright light or physical exercise for non-seasonal and winter depression (Pinchasov et al. 2000). In the past 15 years, this study has been cited in more than a dozen systematic reviews and meta-analyses on exercise for depression (Cass 2001, Jorm et al. 2002, Mallikarjun and Oyebode 2005, Stathopoulou et al. 2006; Winkler et al. 2006, Westrin and Lam 2007, Peiser 2009, Ravindran et al. 2009, Rethorst et al. 2009, Krogh et al. 2011, Josefsson et al. 2014, Gühne et al. 2015, Mead et al. 2009). More recently, has posed the question of whether the reported results on photoand kinesiotherapy can be included in the "alternative interventions" comparison or rather, if they can be judged as comparison of an active treatment (i.e., exercise) with a placebo treatment (i.e., bright light). Such necessity in distinguishing between active and placebo treatments was suggested by Ekkekakis (2015) due to a rising concern about efficacy of bright light therapy as a treatment for depression (National Collaborating Centre for Mental Health and the National Institute for Health and Clinical Excellence 2010: 450, Pichot and Jensen 1989, Light Therapy for Depression and Other Treatment of Seasonal Affective Disorder 2007; Hansen et al. 2008, Mårtensson et al. 2015). Two additional questions have been additionally asked in another publication: whether outcome assessors were blind to the treatment and whether an exercise treatment can last for only one week (Blumenthal and Ong 2009).

Since the time of publication of this paper (Pinchasov et al. 2000) we have additionally collected and partially reported (Putilov 2013, Putilov et al. 2000, Danilenko and Putilov 2005, Putilov and Danilenko 2005a, 2005b) data on several more complex open and blind one-week clinical examinations of these and some other natural antidepressants. Therefore, the major purpose of the present paper was to address the issue of consideration of kinesio- and phototherapy as either "active treatments" "alternative interventions" or "no treatment" control by analyzing a larger set of data on more and less complex one-week antidepressant trials. 


\section{Method}

Clinical effects of one-week antidepressant trials were tested during the winter season at the Medical Academic Hospital near Novosibirsk (55 degrees North) in 138 female study participants. They either did not suffer from depression $(n=33)$ or they were diagnosed as having either seasonal (winter) depression $(n=41)$ or non-seasonal depression $(n=64)$. This sample included 54 participants in clinical trials investigating the therapeutic and physiological effects of one-week mono-treatments that were earlier reported in Pinchasov et al. (2000). The mono-treatments were either a 2-hr 2500 lux cool-white incandescent light from 14:00 to 16:00 or a 1-hr physical exercise from 13:00 to 14:00. Each of the mono-treatment groups included 9 study participants $(9 \times 3 \times 2)$. The three conditions of the mono-treatments were: a) a night of total sleep deprivation followed by 2-hr bright light from 14:00 to 16:00 ( $n=20 ; 8$ seasonal and 12 non-seasonal depressives), b) a night of total sleep deprivation followed by a 1-hr physical exercise under bright light from 12:00 to 13:00 (n16; 5 seasonal and 11 non-seasonal depressives) and c) a night of total sleep deprivation followed by a 1-hr physical exercise under ordinary room light from 13:00 to 14:00 ( $n=12$ non-seasonal depressives). Moreover, three additional groups included 36 participants left without antidepressant therapy for a week during which they passed through examination of their general physical health (10 seasonal, 11 non-seasonal depressives and 15 controls).

Both controls and patients were required to be free from psychotropic drugs, did not suffer from serious general and were not involved in regular physical activities prior to the study. Controls were additionally required to be free of psychiatric illness, sleep complaints and seasonal variations in mood and wellbeing. A history of seasonal difficulties was elicited by self-administration of the Seasonal Pattern Assessment Questionnaire (Rosenthal et al. 1984a). Additionally, the criteria of Rosenthal et al. (1984b) and a 2 to 3-yr history of complete summer remission were required for patients with winter depression (Danilenko and Putilov 1996). Non-seasonal depressives did not meet the criteria for denied seasonal pattern of their depression, but met the criteria for a major or minor depressive disorder or dysthymia (Spitzer et al. 1978).

The 21-item Hamilton Depression Rating Scale (Hamilton 1967) was used for clinical response assessment. It was administered either twice (with a week interval) or three times: before and after total sleep deprivation and after consecutive 7-day treatment with light or/and exercise (Figure 1A or 1B, respectively). Differences between pre- and post-treatment conditions were examined with two-tailed paired student's $t$-test. Two-tailed unpaired student's $t$-test was applied to compare the reduction of depression scores in two different diagnostic groups or after two different one-week treatments. 
Vol. 3, No. $1 \quad$ Putilov et al.: Comparison of Beneficial Effects of Kinesiotherapy...

\section{Results}

Neither clinically nor statistically significant mood improvement was detected in untreated groups (Figure 1A). In contrast, any type of one-week treatment produced significant reduction of depression score in both depressed and non-depressed subjects (Figure 1A).

Winter depression responded better than non-seasonal depression to monotreatment with bright light $(65 \%$ vs. $30 \%, t=4.8, \mathrm{p}<0.001)$. Moreover, the tendency for better response to physical exercise was noted (68\% vs. 57\%, $t=2.0, \mathrm{p}=0.063$ ). However, the responses were similar (Figure 1B) for combination of sleep deprivation with physical exercise under bright light (60\% vs. 65\%, $t=-1.0, \mathrm{p}=0.351)$. Total night sleep deprivation improved mood in seasonally and non-seasonally depressed participants $(t=5.5$ and 9.9, $\mathrm{p}<0.001)$. There was no difference in reductions of depression score between these two diagnostic groups ( $37 \%$ and $44 \%$, respectively; $t=-1.0, \mathrm{p}=0.330$ ).

Figure 1. Responses

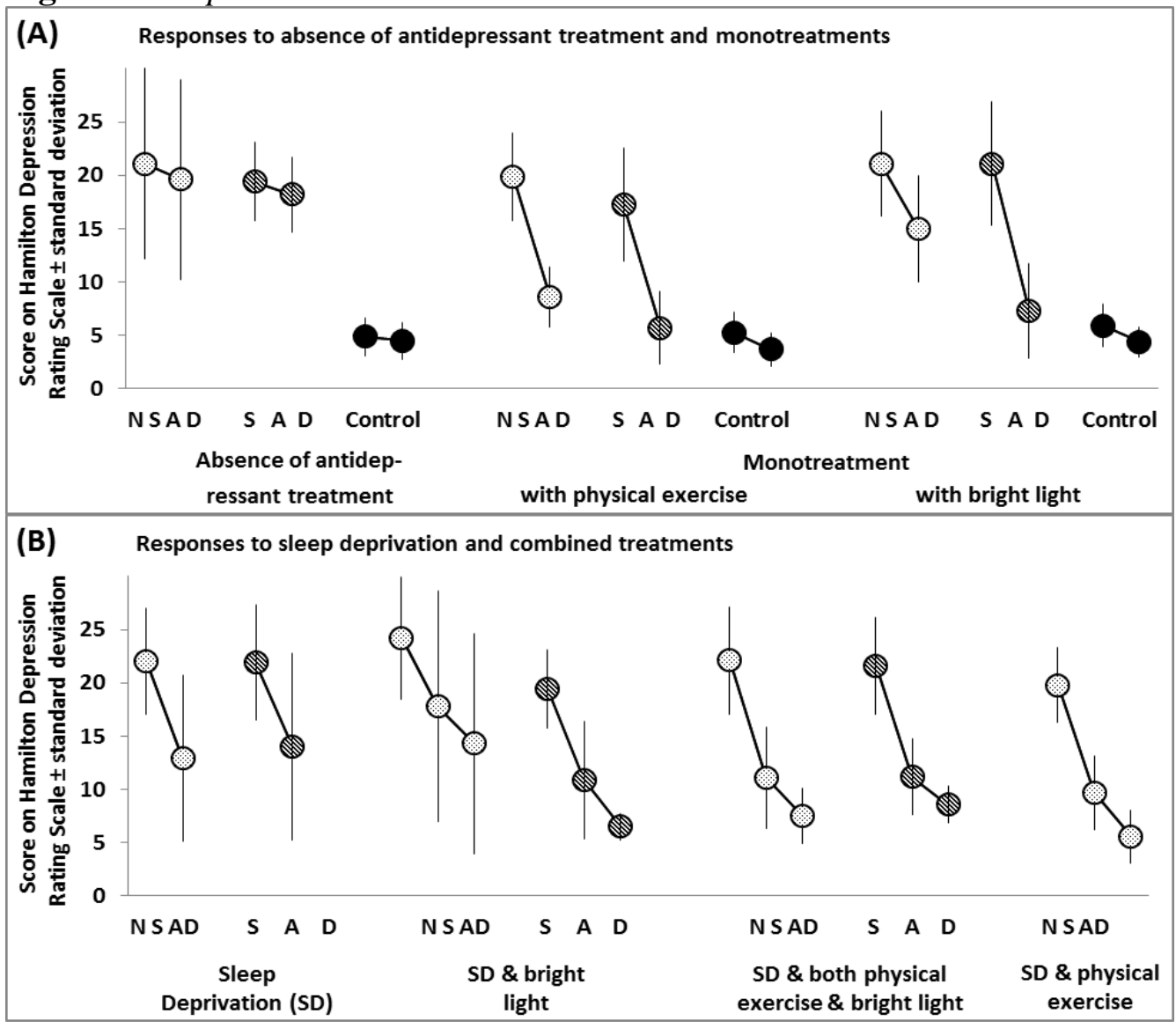

In winter depression, bright light was found to be an effective treatment (Figure 1A). In non-seasonal depression, physical exercise alone or in combination with sleep deprivation was a significantly better treatment 
compared to bright light mono-treatment ( $<<0.001$ for both). Besides, the combination of sleep deprivation with exercise was better treatment than its combination with bright light ( $71 \%$ vs. $44 \%, t=2.7, \mathrm{p}=0.013)$. In treatments following sleep deprivation, further marked reductions of depression score were observed after either bright light exposure or exercise (Figure 1B).

\section{Discussion}

The results illustrated in Figure 1 were in full agreement with the results of several other trials of natural antidepressants for patients with seasonal (winter) depression and healthy controls (Putilov 2013, Putilov et al. 2000, Danilenko and Putilov 2005, Putilov and Danilenko 2005a, 2005b). Previously we found that bright light was an effective treatment irrespective of the time of the day (from $65 \%$ to $70 \%$ ). All combined treatments for winter depression, including placebo, prevented relapse after sleep deprivation. However, further marked reductions of depression score were not detected after blind administration of either melatonin or placebo in the afternoon (i.e., the final reductions were $66 \%$ and $60 \%$ for two "visible" treatments, and only $34 \%$ and $54 \%$ for melatonin and placebo, respectively). The improvement observed in winter depressives after one week spent in a south region was even larger but, nevertheless, it was not significantly better than the effect of one-week treatment with bright light ( $81 \%$ vs. $70 \%)$.

In general, our results suggest that the significant final reductions of depression scores in both depressed and non-depressed women were observed after any type of one-week treatment, such as physical exercise on a bicycle ergometer, bright light exposure, melatonin or placebo intake in the afternoon and short vacation in a south region. The reductions were significant irrespective of whether these treatments were administered alone or in combination with one night of sleep deprivation. However, we also found that the combination of bright light with physical exercise did not bring additional benefits for winter depressives. It seems that there exists a saturation effect of such a short treatment. If, at least, one of two treatment modalities (physical exercise or bright light) ensured an excellent response (i.e., in winter depression), there is no additional benefit when they are combined.

All these findings can be understood in the framework of the idea of a strong modulating effect of placebo on the observed results of antidepressant treatment. When patients were asked to guess on which of two interventions was the active treatment (melatonin vs. placebo intake), these results were found to be the worse and similar for active and placebo treatments. They also were not found to be excellent when it was likely that a "visible" treatment can be regarded by a patient as being ineffective or less effective as compared to a more promising option (bright light vs. physical exercise for non-seasonal depression). Finally, a combination of two promising treatments did not 
produce an additional improvement due to the absence of two separate specific actions of each of two "visible" treatments.

Thus, our results highlight the possibility that such "visible" one-week treatments as kinesiotherapy and phototherapy can work as powerful placebos. It seems that the psychology of depressed individuals is the most important mediator of clinical response to these treatments. In particular, the nature of depression suggests its high sensitivity to encouragement that comes from being involved in a novel antidepressant trial ${ }^{1}$. Therefore, our results allow a recommendation to consider the effects of bright light and physical exercise under the category of Putilov (2013), for more detailed discussion on the nature of beneficial response to treatment for depression and evolutionary roots of placebo response "alternative interventions" in meta-analyses of beneficial action of photo- and kinesiotherapy for mood disorders. It is unlikely that these interventions can be classified as "no treatment" control. For instance, the results illustrated in Figure 1A suggested the absence of spontaneous recovery in the untreated condition. On the other hand, "visibility" of bright light and physical exercise interventions can be a cause of an extremely large contribution of placebo effect to outcomes of such interventions, and hence, they also cannot be definitely named "active treatments".

Depression scored in patients with non-seasonal depression, seasonal depression, and healthy controls (NSAD, SAD, and Control). Figure 1A depression ratings were obtained twice with a one-week interval either in the absence of treatment (left) or before and after one-week mono-treatments with physical exercise (middle) or bright light (right). Figure 1B Ratings were obtained during combined treatments before and after total sleep deprivation, $\mathrm{SD}$ and after the following one-week treatment with bright light and/or physical exercise.

It seems that, so far, only one of the natural treatments for depression, sleep deprivation, has been proved to produce a specific rather than a placebo effect. Although, psychotherapeutic mechanisms can contribute to its antidepressant action, they do not provide a complete explanation for the observed improvement of mood (Wu and Bunney 1990, Wirz-Justice and Van den Hoofdakker 1999). Moreover, the early studies ruled out the possibility to explain the antidepressant effect of sleep deprivation by the influence of such psychological factors as patients' positive expectations and attitudes, because favorite clinical responses were also documented when patients were told that this intervention served an aim of either diagnostic (Pflug and Tölle 1971) or biological rhythm assessment (Gerner et al. 1979). The remaining problem with antidepressant action of sleep deprivation is that this action is short-lived (till the morning following the first sleep episode) and other interventions are usually required for its stabilization. Nevertheless, we see no serious obstacles in recommending interventions with bright light and physical exercise as safe,

\footnotetext{
${ }^{1}$ See Putilov (2013) for more detailed discussion on the nature of beneficial response to treatment for depression and evolutionary roots of placebo response.
} 
cheap, rapid and effective antidepressants. This is especially the case, for those seasonal and non-seasonal depressives who do not respond to drug medications, prefer unconventional and non-pharmacological treatments and suffer from depression in mild or moderate rather than severe, chronic or recurrent forms.

\section{Conclusions}

The results of natural antidepressant therapies for seasonal and nonseasonal depression revealed a highly significant clinical response of depressed female study participants to one-week mono - and combined treatments. We found that i) a one-week kinesiotherapy was equally beneficial for seasonal and winter depression, ii) a treatment with bright light produced a similarly strong antidepressant response only in winter depressives, iii) a week of bright light therapy and/or kinesiotherapy was able to prevent relapse after night sleep deprivation and iv) mood was even further improved in seasonal and winter depressives after such "visible" treatments. However, if at least one of treatment modalities ensured excellent response, there was no additional benefit from their combination. Therefore, it can be generally concluded that our results highlighted the possibility that most of these one-week treatments can work as powerful placebos.

\section{Acknowledgments}

The studies of AP were supported by the Russian Foundation for Basic Research (grants 07-06-00263-a, 10-06-00114-a, 13-06-00042-a, and 16-0600235-a), and the Russian Foundation for Humanities (grants 06-06-00375-a, 12-06-18001-e, and 15-06-10403-a). We are thankful to Dr. Elena Y. Poljakova for her help in assessment of depression in some study participants.

\section{References}

Andrews G (2001) Placebo response in depression: bane of research, boon to therapy. British Journal of Psychiatry 178: 192-194.

Antonuccio DO, Danton WG, DeNelsky GY, Greenberg RP, Gordon JS (1999) Raising questions about antidepressants. Psychotherapy and Psychosomatics 68: 3-14.

Blumenthal JA, Ong L (2009) A commentary on "Exercise and Depression" (Mead et al., 2009): And the verdict is ... . Mental Health and Physical Activity 2(2): 9799.

Cass H (2001) Update on seasonal affective disorder: light therapy and herbs relieve many symptoms. Alternative and Complementary Therapies 7(1): 5-7. 
Danilenko KV, Putilov AA (1996) The importance of full summer remission as a criterion for the diagnosis of seasonal affective disorder. Psychopathology 29: 230-235.

Danilenko KV, Putilov AA (2005) Melatonin treatment of winter depression following total sleep deprivation: waking EEG and mood correlates. Neuropsychopharmacology 30: 1345-1352.

Gerner RH, Post RM, Fillin JC, Bunney WE (1979) Biological and behavioral effects of one night's sleep deprivation in depressed patients and normals. Journal of Psychiatric Research 15:21-40.

Gühne U, Weinmann S, Arnold K, Becker T, Riedel-Heller SG (2015) S3 guideline on psychosocial therapies in severe mental illness: evidence and recommendations. European Archives of Psychiatry and Clinical Neuroscience 265(3): 173-188.

Hamilton M (1967) Development of a rating scale for primary depressive illness. British Journal of Social and Clinical Psychology 6: 278-296.

Hansen V, Skre I, Lund E (2008) What is this thing called "SAD"? A critique of the concept of Seasonal Affective Disorder. Epidemiologia e psichiatria sociale 17(2): 120-7.

Ekkekakis P (2015) Honey, I shrunk the pooled SMD! Guide to critical appraisal of systematic reviews and meta-analyses using the Cochrane review on exercise for depression as example. Mental Health and Physical Activity 8: 21-36.

Joffe RT, Sokolov S, Streiner D (1996) Antidepressant treatment of depression: a meta-analysis. Canadian Journal of Psychiatry 41: 613-616.

Jorm AF, Christensen H, Griffiths KM, Rodgers B (2002) Effectiveness of complementary and self-help treatments for depression. Medical Journal of Australia 176(Supplement): 84-96.

Jorm, AF, Korten AE, Jacomb PA, Christensen H, Rodgers B, Pollitt P (1997) "Mental health literacy": a survey of the public's ability to recognize mental disorders and their beliefs about the effectiveness of treatment. Medical Journal of Australia 166: 182-186.

Josefsson T, Lindwall M, Archer T (2014) Physical exercise intervention in depressive disorders: Meta-analysis and systematic review. Scandinavian Journal of Medicine and Science in Sports 24(2): 259-272.

Khan A, Warner HA, Brown WA (2000) Symptom reduction and suicide risk in patients treated with placebo in antidepressant clinical trials: an analysis of the food and drug administration database. Archives of General Psychiatry 57: 311317.

Kirsch I, Deacon BJ, Huedo-Medina TB, Scoboria A, Moore TJ, Johnson BT (2008) Initial severity and antidepressant benefits: a meta-Analysis of data submitted to the FDA. PLoS Medicine 5: 260-269.

Krogh J, Nordentoft M, Sterne JAC, Lawlor DA (2011) The effect of exercise in clinically depressed adults: Systematic review and meta-analysis of randomized controlled trials. Journal of Clinical Psychiatry 72(4): 529-538.

Lawlor DA, Hopker SW (2001) The effectiveness of exercise as an intervention in the management of depression: Systematic review and meta-regression analysis of randomized controlled trials. British Medical Journal 322: 1-8.

Light Therapy for Depression, and Other Treatment of Seasonal Affective Disorder: A Systematic Review (2007) Revision of chapter 9 in SBU report. Treatment of Depression. 166(2/December). 
Mallikarjun P, Oyebode F (2005) Understanding seasonal affective disorder. Practitioner 249(1667): 116-119.

Mårtensson B, Pettersson A, Berglund L, Ekselius L (2015) Bright white light therapy in depression: a critical review of the evidence. Journal of Affective Disorders 182: $1-7$.

Martinsen EW (2008) Physical activity in the prevention and treatment of anxiety and depression. Nordic Journal of Psychiatry 62(S47): 25-29.

Mead GE, Morley W, Campbell P, Greig CA, McMurdo M, Lawlor DA (2009) Exercise for depression. Cochrane Database Systematic Reviews (3). Art. No.: CD004366.

Moncrieff J (2002) The antidepressant debate. British Journal of Psychiatry 180: 193194.

Moncrieff J, Wessely S, Hardy R (1998) Meta-analysis of trials comparing antidepressants with active placebos. British Journal of Psychiatry 172: 227-231.

Murray CJ, Lopez AD (1996) Global Health Statistics. Cambridge, MA: Harvard School of Public Health (Global Burden of Disease and Injury Series, vol. II).

National Collaborating Centre for Mental Health and National Institute for Health and Clinical Excellence (2010) The Treatment and Management of Depression in Adults (Updated eds.). Leicester and London: The British Psychological Society and the Royal College of Psychiatrists.

Peiser B (2009) Seasonal affective disorder and exercise treatment: a review. Biological Rhythm Research 40(1): 85-97.

Pflug B, Tölle R (1971) Disturbance of the 24-hr rhythm in endogenous depression and the treatment of endogenous depression by sleep deprivation. International Pharmacopsychiatry 6: 187-196.

Pichot JJ, Jensen PS (1989) Seasonal affective disorder: SAD or FAD? Jefferson Journal of Psychiatry 7: 41-50.

Pinchasov BB, Shurgaja AM, Grischin OV, Putilov AA (2000) Mood and energy regulation in seasonal and non-seasonal depression before and after midday treatment with physical exercise or bright light. Psychiatry Research 94(1): 2942.

Putilov A (2013) Natural treatments for seasonal and non-seasonal depression: a review of literature and comparison of antidepressant responses. Scientific Journal of Review 2(1): 11-36.

Putilov AA, Donskaya OG, Jafarova OA, Danilenko KV (2000) Waking EEG power density in hypersomnic winter depression. Society of Light Treatment and Biological Rhythms, 12 (Abstracts): 24.

Putilov AA, Danilenko, KV (2005a) Antidepressant effects of light therapy and "natural" treatments for winter depression. Biological Rhythm Research 36: 423437.

Putilov AA, Danilenko, KV (2005b). Antidepressant effects of combination of sleep deprivation and early evening treatment with melatonin or placebo for winter depression. Biological Rhythm Research 36: 389-403.

Ravindran AV, Lam RW, Filteau MJ, Lespérance F, Kennedy SH, Parikh SV, Patten SB (2009) Canadian network for mood and anxiety treatments (CANMAT) clinical guidelines for the management of major depressive disorder in adults. V. Complementary and alternative medicine treatments. Journal of Affective Disorders 117(Supplement 1): 54-64. 
Rethorst CD, Wipfli BM, Landers DM (2009) The antidepressive effects of exercise: a meta-analysis of randomized trials. Sports Medicine 39(6): 491-511.

Rosenthal NE, Sack DA, Gillin JC, Lewy AJ, Goodwin RK, Davenport Y, Mueller PS, Newsome DA, Wehr TA (1984a): Seasonal affective disorder: a description of the syndrome and preliminary findings with light therapy. Archives of General Psychiatry 41: 72-80.

Rosenthal NE, Bradt GH, Wehr, TA (1984b) Seasonal Pattern Assessment Questionnaire. Bethesda, MD: National Institute of Mental Health.

Spitzer RL, Endicott J, Robins E (1978) Research diagnostic criteria: rationale and reliability. Archives of General Psychiatry 35: 773-782.

Stathopoulou G, Powers MB, Berry AC, Smits JAJ, Otto MW (2006) Exercise interventions for mental health: a quantitative and qualitative review. Clinical Psychology: Science and Practice 13(2): 179-193.

Üstün TB, Ayuso-Mateos JL, Chatterji S, Mathers C, Murray CJL (2004) Global burden of depressive disorders in the year 2000. The British Journal of Psychiatry 184: 386-392.

Walsh BT, Seidman SN, Sysko R, Gould M (2002) Placebo response in studies of major depression: variable, substantial, and growing. Journal of the American Medical Association 287: 1840-1847.

Westrin $\AA$, Lam RW (2007) Seasonal affective disorder: a clinical update. Annals of Clinical Psychiatry 19(4): 239-246.

Winkler D, Pjrek E, Iwaki R, Kasper S (2006) Treatment of seasonal affective disorder. Expert Review of Neurotherapeutics 6(7): 1039-1048.

Wirz-Justice A, Van den Hoofdakker RH (1999) Sleep deprivation in depression: what do we know, where we go? Biological Psychiatry 46(4): 445-53.

Wu J C, Bunney WE (1990) The biological basis of an antidepressant response to sleep deprivation and relapse: review and hypothesis. American Journal of Psychiatry 147: 14-21. 